\title{
Optimizing Life Quality through Circadian Bioprocessing of Lifestyle: Founding a Civic Science
}

\section{Akbar Nikkhah*}

Chief Highly Distinguished Professor, Department of Animal Sciences, University of Zanjan, Iran

\section{Summary}

This perspective public policy article increases public consciousness of the untraveled highway of 'circadian lifestyle timing' to optimizing integrative metabolism and health in the new postmodern era. The most recent discoveries in livestock, rat and human nutritional physiology contributed to the emerging science of 'chronophysiology management'. This science is concerned with circadian rhythms of cell metabolism and how they should be synchronized with lifestyle rhythms including timing of eating, exercising, resting and photoperiod.

\section{Innovative Ideological Discussion}

Quality life may be accomplished effectively through circadian rhythmic fitting of human internal physiology with the external environment [1-4]. For instance, recent findings revealed that ruminants as irreplaceable working models with sophisticated metabolism and physiology respond dramatically to timing of eating $[5,6]$. Dairy cows fed in morning vs. evening under thermo neutral and controlled environments produced greater milk energy and in some cases consumed greater feed that is a sign of good metabolic health [6,7]. These findings were substantiated in following studies [8]. In addition, it is generally known that glucose tolerance and insulin sensitivity in human are impaired as day leaves for night $[9,10]$. The fact that evening-fed cows produce more milk and may eat more feed than their morning-fed peers, stems from their considerably higher metabolic turnover of peripheral tissues, when compared to human. However, the unique brain metabolism in human must be contemplated differently when aiming to interpret animal data for interventions in human metabolism and medicine.

The science generated mainly over the last few decades established that when to eat matters greatly for public health. Insulin is not required very much in high-producing cows since they need not to deposit but instead to secret nutrients out of the body. In other words, insulin action in high-producing ruminants is rather restricted to nutrient oxidation in fuelling splanchnic tissue's energy expenditure. In contrast, human metabolism is greatly dependent on and responsive to insulin all the time. Thus, in view of the evolutionary human metabolism, less glucose and thus less insulin have been required overnight when the body must rest and not highly metabolize. As a result, human has not evolved to develop a high-capacity insulin-dependent glucose and amino acid metabolism during evening and night times. As such, should energizing foods be greatly supplied overnight, when the body is not prepared to manage, chances are that impaired intermediary and integrative metabolism occur. However, more research is required before global guidelines on optimal times of eating, exercising, and resting can be definitively formulated.

Fundamentally, any strategy that keeps human lifestyle adequately close to its natural environment would be fairly optimal $[11,12]$. Frequent but small diurnal meals and no major nocturnal meal is what the nature has taught human. Fitting the internal rhythms of human physiology and metabolism with those of the external environment may be optimally achieved through modulating circadian timing of eating, exercising, resting and any other major daily task [13,14]. This practice is of increasing importance in the modern lifestyle, especially in pregnant women, overweight and obese individuals, and those suffering from or exposed to oncogenesis and cardiovascular deficiencies $[15,16]$.

\section{Nutshell Conclusion}

The integrative public education must concentrate on signifying the importance of circadian timing of lifestyle to ensure that internal physiology is properly managed to be adequately harmonized with the external environment. This can assure that the civic knows and can feasibly practice how prevention is superior to treatment in overcoming metabolic disorders and various types of cancer. It is time to make science workable for all.

\section{Acknowledgments}

The Ministry of Science Research and Technology, National Elite Foundation, and University of Zanjan are thanked for supporting the author's international initiatives and global programs of optimizing science edification in the third millennium.

\section{References}

1. Nikkhah A (2012) Eating time modulations of physiology and health: life lessons from human and ruminant models. Iran J Basic Med Sci 15: 891-899.

2. Nikkhah A (2011) Ruminant chronophysiological management: an emerging bioscience. Open Access Anim Physiol 3: 9-12.

3. Nikkhah A (2013) Chronophysiology of ruminant feeding behavior and metabolism: an evolutionary review. Biol Rhythm Res 44: 197-218.

4. Nikkhah A (2011) Bioscience of ruminant intake evolution: feeding time models. Adv Biosci Biotechnol 2: 271-274.

5. Nikkhah A (2014) Timing of feeding: a postmodern management strategy to modulate chronophysiological rhythms in rumen fermentation kinetics. Biol Rhythm Res 45: 533-540.

6. Nikkhah A, Furedi CJ, Kennedy AD, Crow GH, Plaizier JC (2008) Effects of feed delivery time on feed intake, milk production, and blood metabolites of dairy cows. J Dairy Sci 91: 4249-4260.

7. Nikkhah A (2012) Time of Feeding an Evolutionary Science. Lap Lambert Publishing, GmbH \& Co. KG, Germany.

8. Nikkhah A, Furedi CJ, Kennedy AD, Scott SL, Wittenberg KM, et al. (2010) Morning vs. evening feed delivery for lactating dairy cows. Can J Anim Sci 91 : 113-122.

*Corresponding author: Akbar Nikkhah, Chief Highly Distinguished Professor Department of Animal Sciences, Faculty of Agricultural Sciences, University of Zanjan, Zanjan, Iran, National Elite Foundation, Tehran, Iran, Tel: +98-24-350328-01; Fax: +98-24-350-332-02; E-mail: nikkhah@znu.ac.ir

Received May 27, 2015; Accepted May 29, 2015; Published June 02, 2015

Citation: Nikkhah A (2015) Optimizing Life Quality through Circadian Bioprocessing of Lifestyle: Founding a Civic Science. J Bioprocess Biotech 5: e133 doi:10.4172/2155-9821.1000e133

Copyright: @ 2015 Nikkhah A. This is an open-access article distributed under the terms of the Creative Commons Attribution License, which permits unrestricted use, distribution, and reproduction in any medium, provided the original author and source are credited. 
Citation: Nikkhah A (2015) Optimizing Life Quality through Circadian Bioprocessing of Lifestyle: Founding a Civic Science. J Bioprocess Biotech 5: e133 doi:10.4172/2155-9821.1000e133

Page 2 of 2

9. Nikkhah A (2014) Eating timing and diabetes. Int J Diabetol Vasc Dis Res 2: 101

10. la Fleur SE, Kalsbeek A, Wortel J, Fekkes ML, Buijs RM (2001) A daily rhythm in glucose tolerance: a role for the suprachiasmatic nucleus. Diabetes 50 : 1237-1243.

11. Nikkhah A (2015) Crumbling the rising super-cancer of obesity by optimizing frequency and timing of food meals. Adv Weigh Manag Obes Cont.

12. Nikkhah A (2015) Nature as an Ideal Rhythm Model for Optimal Cardiovascular Physiology and Health. Int J Diabetol Vasc Dis Res 3: 1-2.
13. Nikkhah A (2015) Secure Weight Management via Fitting Circadian Patterns of Physical Activity, Resting and Eating. Adv Obes Weight Manag Cont 2: 023.

14. Nikkhah A (2015) Effective Weight Management in Periparturient Women through Optimizing Eating Timing: A Novel Global Approach. Adv Obes Weight Manag Cont 2: 018.

15. Nikkhah A (2015) Harmonizing Eating and Exercise Circadian Rhythms for Optimal Glucose-Insulin and Vascular Physiology. Int J Diabetol Vasc Dis Res 3: 87-88.

16. Nikkhah A (2015) Breast Safety Progress through Exercise-Driven Lactation: A Pragmatic Bioprocess to Prevent Cancer. J Bioprocess Biotech 5: e127. 